\title{
Dual-fuel combustion in a tangential PC-fired boiler of type OP-230 - computational simulations
}

\author{
Przemysław Motyl ${ }^{1, *}$, and Jan Lach $^{2}$ \\ ${ }^{1}$ Kazimierz Pulaski University of Technology and Humanities in Radom, Faculty of Mechanical Engineering, Malczewskiego 29, \\ 26-600 Radom, Poland \\ ${ }^{2}$ Bialystok University of Technology, Faculty of Engineering Management, Ojca Tarasiuka 2, 16-001 Kleosin, Poland
}

\begin{abstract}
Syngas co-firing in coal fired boilers can be one of the prospective technologies which may help to retrofit some of still functioning older boilers. This study focuses on the results of CFD simulations of wood biomass-derived syngas co-firing with coal in an older mid-sized tangential PC-fired boiler of type OP-230. The design and the implementation of the combustion process predispose the boiler to the connection with the biomass gasifier in which low calorific syngas from solid raw biomass gasification can be produced and next used as a supplemental fuel in the coal furnace. The simulations were performed to predict the influence of the improvement of the air staging via the dual-fuel technique based on the indirect co-firing technology on both the reductions in $\mathrm{NO}_{\mathrm{x}}$ emissions relative to the baseline (no syngas) and the residence time of syngas particles in a zone with the temperature higher than $1123 \mathrm{~K}$. This way one can determine whether the boiler can be recommended to indirect co-firing of syngas derived from agricultural residues biomass or SRF gasification containing such troublesome components as chlorine and alkali.
\end{abstract}

\section{Introduction}

One of the routes to accomplish coal and biomass promising co-firing technology, referred as a clean and environmentally friendly low-emission indirect co-firing, involves replacing several percent of the coal with syngas produced from the highly efficient on-site gasification of a wide range of solid raw or modified biomass resources usually in a commercial fluidised bed gasifier. Many coal gasification technologies are in widespread commercial use $[1,2]$ while the technically viable biomass gasification technologies are still being developed in lab-scale, improved in pilot and demo installations and successively implemented into engineering practice in commercial installations $[3,4]$. Experiences with the commercial-scale implementations of the biomass indirect co-firing technology were acquired mainly in Finland but also in Austria, Belgium and the Netherlands. The first global implementation is made at the Kymijärvi PC-fired CHP-plant [5]. Further significant examples are the Zeltweg PC-fired power plant [6], the Electrabel Ruien fossil fuel-fired power station [7] and the Amercentrale coal-fired CHP unit of Essent in Geertruidenberg [8]. Particular attention should be paid to the world's largest Vaskiluodon Voima plant in Vaasa located at the Vaskiluoto 2 power plant [9] and supplied by Metso. This way, the indirect co-firing of biomass in existing coal-fired boilers increasingly gain market acceptance but is not yet the most attractive option of co-firing projects due mainly to economic reasons. A handful of examples of its industrial applications listed above translates into still numerous research studies including our own one to the problem. We will limit ourselves here to a concise reference to the results of indirect co-firing simulations reported in a few of selected papers. Therefore, the detailed analysis focused on the reduction in $\mathrm{NO}_{\mathrm{x}}$ emissions relative to the baseline depending on the paper rejects-derived syngas composition, heat input replacement and furnace stoichiometry in a 70t/h-steam coal-fired industrial boiler is given in [10]. The similar analysis of biomass-derived syngas co-firing with a lignite in a $600 \mathrm{MWe}$ tangentially fired boiler is taken in [11]. The numerical approach to the coal co-firing with the product gas from sewage sludge gasification in the PC-fired OP-650 boiler at the Kozienice power plant in Poland is demonstrated in [12]. The impact of the share of product gas from biodegradable waste gasification and LCV gas quality on a $230 \mathrm{t} / \mathrm{h}$ dual fuel pulverized coal-gas fired boiler parameters and performance is reported in [13]. The effect of the biomass-derived syngas fraction in the mixture with natural gas on basic co-firing parameters in gas-fired fuel systems is examined in [14]. Our study is focused on the 3D inexpensive full-scale numerical approach based on such a powerful computational tool as CFD code known as Fluent [15] for modelling the cofiring of coal and wood biomass-derived syngas which is injected into the furnace of an older mid-sized tangentially PC-fired boiler of type OP-230 through new dedicated nozzles. Their relatively flexible arrangement and the choice of the right value of syngas volumetric flow rate can ensure the operational parameters,

Corresponding author: p.motyl@gmail.com 
primarily the right thermal effect guaranteeing the furnace heat balance, and technological conditions making possible to reduce $\mathrm{NO}_{\mathrm{x}}$ emissions compared to that of coal combustion originally regulated by means of inexpensive standard air staging technique. The design and the implementation of the combustion process predispose the boiler to the connection with the biomass gasifier. Computational three-dimensional modelling of tangentially fired PC-boilers using CFD is widely regarded as effective calculation tool. Our goal is to determine whether the level of $\mathrm{NO}_{\mathrm{x}}$ emissions resulting from modifying the air staging based on the indirect cofiring technology, i.e. via the dual-fuel technique, corresponds to the prospective more restrictive environmental protection regulations. Then indirect cofiring could be one of the effective technologies for the boiler retrofit. Compared to the least complicated and attractive for investors direct biomass co-firing, it offers such important advantages as: (i) the avoidance of coal only ash properties altering due to the separate storage of slag and ash from gasification and syngas co-firing which means that fly ash can meet the quality standards for use of its in concrete; (ii) the resulting high flexibility with regards to the choice of fuel biomass for gasification including not only wood, wood waste and residual wood waste but even wide range of biomass containing high alkali metals and chlorine or difficult for the pre-treatment; (iii) reduction of the risk of the ash softening, the deposition of pollutants on heat exchange surfaces in the boiler and SCR catalysts, and reduction of the impact of high-temperature corrosion on steel structural elements of boilers as a result of limiting chlorine mobility already in the gasifier; and (iv) simplification of the eventual biomass pre-treatment processes including the elimination of risky problems both at the stage of co-milling biomass with coal and their separate milling before co-firing in coal burners or combustion in dedicated biomass burners. When PCfired boilers of type OP are retrofitted by their conversion into fluidized bed boilers, then different types of biomass of forest and non-forest origin can be combusted but the high number of alkaline compounds contained in agricultural biomass and waste from agrifood processing can result in severe bed agglomeration. Although the indirect co-firing is still not very popular, it is considered safer, more effective (efficient energy recovery) and more environmentally friendly than direct co-firing. We limit ourselves to the prediction of reductions in $\mathrm{NO}_{\mathrm{x}}$ emissions relative to the baseline (no syngas) for a priori one adopted arrangement of syngas nozzles and heat input replacement.

\section{Boiler description}

The boiler manufactured by Rafako that was examined is shown in Fig.1. The size of a tangentially fired furnace is $8.115 \times 23.2 \times 7.855 \mathrm{~m}$. The lowemission pulverised coal combustion system based on low-emission burners and two-stage combustion with OFA nozzles allows to reduce $\mathrm{NO}_{\mathrm{x}}$ emissions below 400 $\mathrm{mg} / \mathrm{Nm}^{3}\left(6 \% \mathrm{O}_{2}\right)$ and to keep the amount of unburned coal in fly ash below $5-7 \%$ depending on the ash content in coal. The RI (Rapid Ignition) - JET coal burners (Fig.2) are located at three elevations in the corners of furnace chamber (Fig.3) which is typical for small boilers.

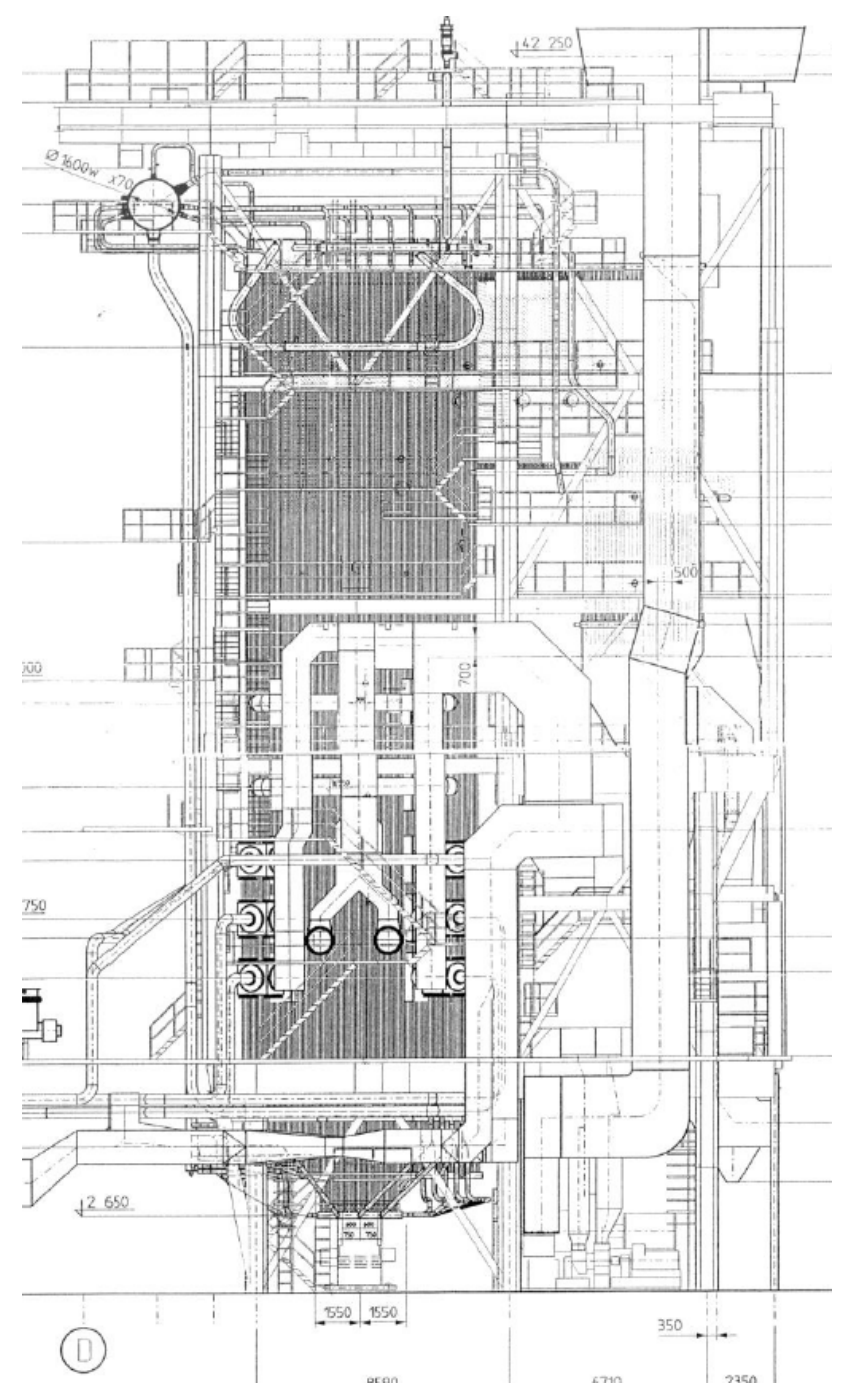

Fig. 1. Schematic of the boiler [16].

There are four burners at each elevation. Thus, the boiler is equipped with twelve burners. They are designed and made in Finland, by Fortum Engineering Ltd. and Osatoes Ltd., respectively. During normal boiler operation four of them on one elevation are out of service. Combustion air supplied to the burner is divided into three parts: primary, secondary and tertiary air. The burner ensures rapid and effective ignition and flame stabilization due to (i) the pulverized coal concentrator whose aerodynamics favors the achievement of a rich dust mixture at the perimeter of the pipe of primary air and dust; (ii) the special flame stabilization ring supporting the ignition of this mixture; (iii) the large reducing combustion zone achievable by separating the supplied secondary and tertiary air; (iv) the low $\mathrm{NO}_{\mathrm{x}}$ level due to effective secondary air swirling; and (v) efficient burnout of the char particles using the tertiary air. Combustion in the primary air zone occurs at extreme sub-stoichiometry. Due to the reducing 
compounds, NO formed is dispersed in the secondary air zone. Separation of the tertiary air from combustion in the secondary air zone is achieved by means of control sleeve and an adjustable turbulence of both flows.

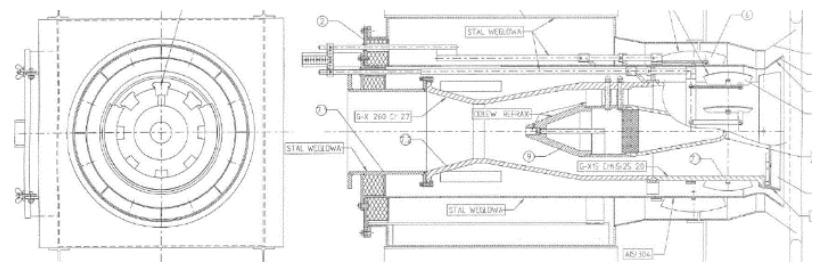

Fig. 2. RI (Rapid Ignition) - JET coal burner [16].

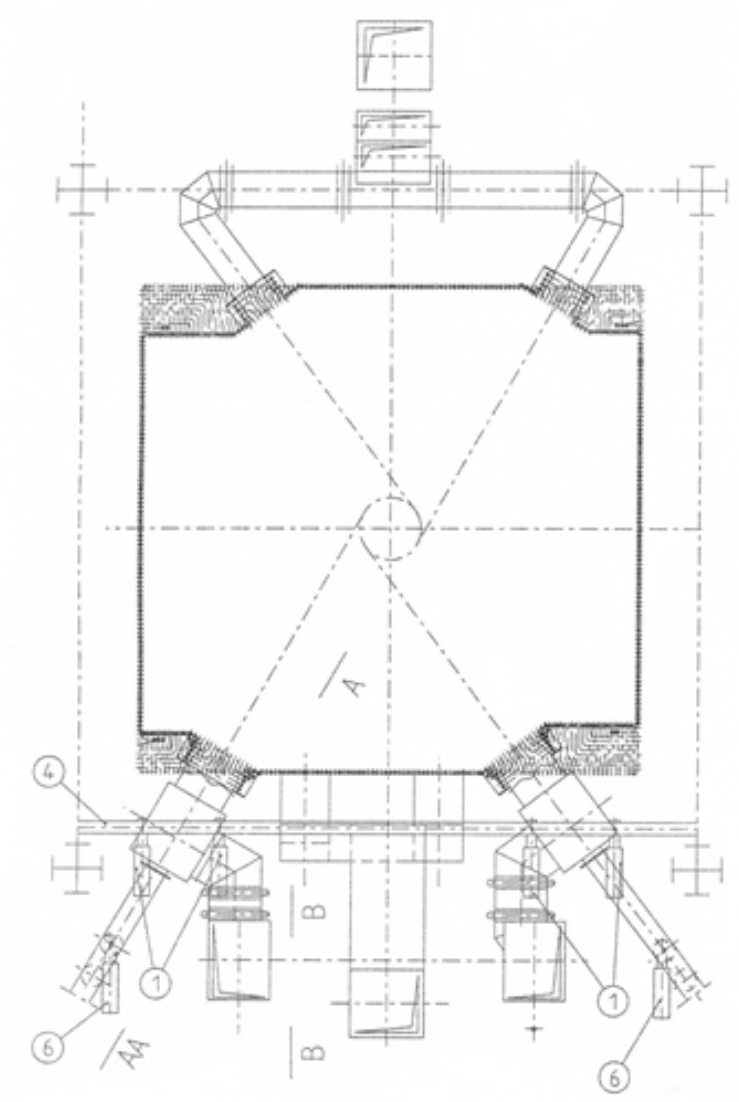

Fig. 3. Arrangement of burners [16].

Devices for secondary and tertiary air regulation are equipped with manually adjustable blades forcing the mixing of air flows which improves the combustion process. Such an effect is also due to dust nozzle having shape of Venturi orifice equalizing the concentration of particles in the flowing air and at the same time preventing a backward movement of the flame. Flame shape stabilization by a ring equipped with "ceramic teeth" (Fig.2) is based on two phenomena: (1) the "teeth" cause turbulent motion of the coal particles at the outlet of the burner throat; and (2) the open space between the burner throat and the conical ring enforces a stable turbulent movement of coal-air mixture. In this way, there is more time to ignite. The pulverized coal concentrator focuses coal particles on the walls of the coal feed pipe. Thus, both the stabilizing ring and the dust concentrator play a key role in ensuring lowemissions combustion. The boiler is equipped with eight
OFA nozzles located at two elevations (Fig.4). Therefore, there is some flexibility in the optimal setting of fuel and air, which in particular allows a large burnout of coal. Additionally, in the boiler we have to deal with the implementation of the combustion air staging.

\section{Computational problem}

For the purpose of analysis of the dual-fuel combustion in the boiler (Fig.1), the model of the furnace has been developed. The mathematical modelling focuses on commercial CFD code Fluent [10] in release 19. The computational mesh constructed over the region of the furnace consisted of about $2.710^{6}$ elements of the Polyhedra type. Data enabling the determination of boundary conditions for the numerical model were obtained from the boiler operating manual [16]. The most important of them are given in Table 1.

Finite-Rate/Eddy-Dissipation model [15] used to modelling combustion of coal and co-firing coal with wood biomass derived syngas is constructed by making use of the following equations:

$$
\begin{aligned}
& \mathrm{C}_{0.89} \mathrm{H}_{5.82} \mathrm{O}_{0.68} \mathrm{~N}_{0.1728}+1.56 \mathrm{O}_{2} \rightarrow 0.89 \mathrm{CO}+2.91 \mathrm{H}_{2} \mathrm{O}+ \\
& 0.0864 \mathrm{~N}_{2} \\
& \mathrm{C}(\mathrm{s})+0.5 \mathrm{O}_{2} \rightarrow \mathrm{CO} \\
& \mathrm{C}(\mathrm{s})+\mathrm{CO}_{2} \rightarrow 2 \mathrm{CO} \\
& \mathrm{C}(\mathrm{s})+\mathrm{H}_{2} \mathrm{O} \rightarrow \mathrm{H}_{2}+\mathrm{CO} \\
& \mathrm{H}_{2}+0.5 \mathrm{O}_{2} \rightarrow \mathrm{H}_{2} \mathrm{O} \\
& \mathrm{CO}+0.5 \mathrm{O}_{2} \rightarrow \mathrm{CO}_{2} \\
& \mathrm{CH}+2 \mathrm{O}_{2} \rightarrow \mathrm{CO}_{2}+2 \mathrm{H}_{2} \mathrm{O}
\end{aligned}
$$

The implementation of the standard k- $\varepsilon$ turbulence model [15] enables the turbulent Reynolds equations to be closed. The Discrete Ordinates radiation model was used to simulate radiation heat transfer. The gas phase absorption coefficients are calculated using the weighted-sum-of-grey gases model (WSGGM). The assumed chemical composition of coal by percentage $(\%$ by weight, i.e. wt $\%$ ) was as follows: carbon [C], 60.58; hydrogen $[\mathrm{H}], 4.40$; oxygen $[\mathrm{O}], 8.20$; nitrogen $[\mathrm{N}]$, 1.30 ; sulphur $[\mathrm{S}], 0.22$; chlorine $[\mathrm{Cl}], 0.30$; ash $[\mathrm{A}]$, 12.60, and moisture [W], 12.40. Its LHV was assumed to be equal to $23.44 \mathrm{MJ} / \mathrm{kg}$. The wood biomass-derived syngas composition by percentage ( $\%$ by volume) was as follows: $\mathrm{CO}_{2}, 7.3 ; \mathrm{CH}_{4}, 3.0 ; \mathrm{CO}, 21.8 ; \mathrm{H} 2,7.6 ; \mathrm{N}_{2}, 41.3$; and $\mathrm{H}_{2} \mathrm{O}-19.0$ [17]. In order to show the influence of the improvement of the air staging via the dual-fuel technique based on the indirect co-firing technology, two cases were modelled: the baseline (no syngas - Case 0) and co-firing of coal with wood biomass-derived syngas injected into the combustion chamber via new dedicated nozzles (Case 1). Case 0 is considered as a reference one. For Case 1 heat input replacement was assumed as equal to $15 \%$. Four syngas nozzles were located below the OFA nozzles (Fig.4). 


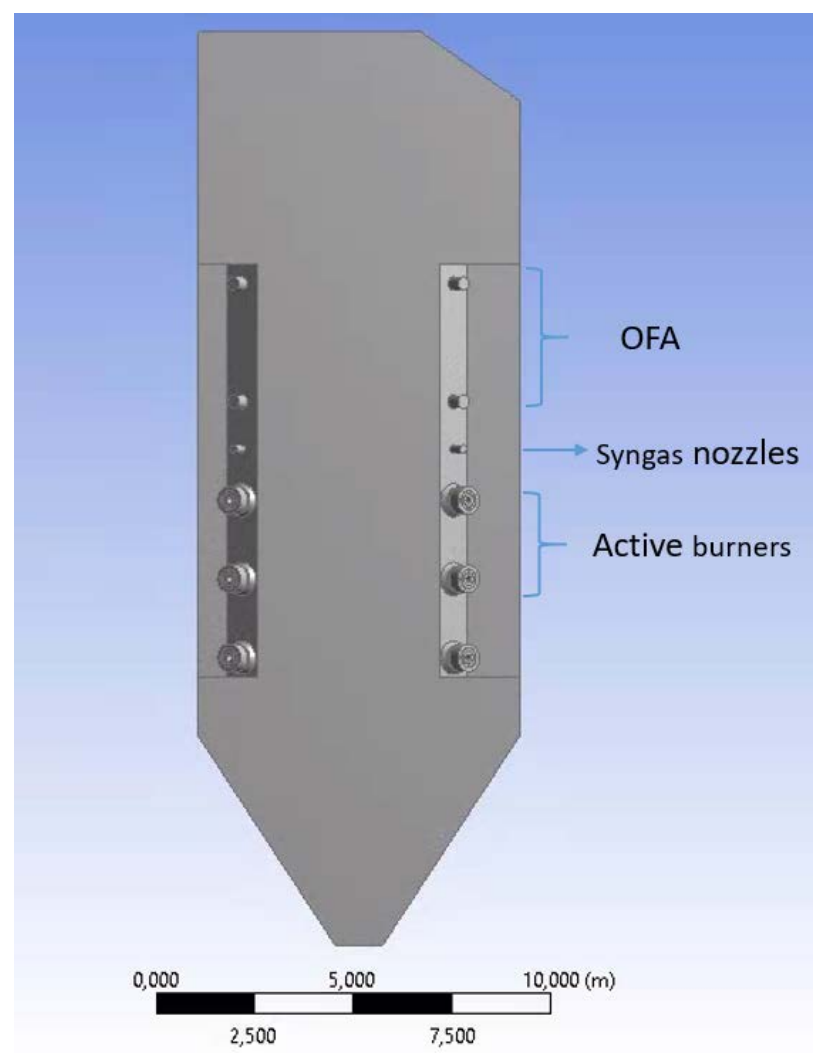

Fig. 4. Location of syngas nozzles in the furnace.

Table 1. Boiler operating conditions (full load).

\begin{tabular}{|l|c|c|}
\hline \multicolumn{1}{|c|}{ Parameter } & Unit & Value \\
\hline Coal feed rate/burner & $\mathrm{kg} / \mathrm{s}$ & 1 \\
\hline Primary air flow rate/burner & $\mathrm{kg} / \mathrm{s}$ & 2 \\
\hline Secondary air flow rate/burner & $\mathrm{kg} / \mathrm{s}$ & 4.5 \\
\hline Air flow rate/OFA nozzle & $\mathrm{kg} / \mathrm{s}$ & 2.3 \\
\hline Coal-air mixture temperature & $\mathrm{K}$ & 373 \\
\hline Primary air temperature & $\mathrm{K}$ & 373 \\
\hline Secondary air temperature & $\mathrm{K}$ & 573 \\
\hline OFA temperature & $\mathrm{K}$ & 573 \\
\hline Steam capacity & $\mathrm{t} / \mathrm{h}$ & 230 \\
\hline
\end{tabular}

\section{Results and discussion}

The adopted location of additional nozzles dedicated to supplying syngas to the combustion chamber is only one of the possible solutions. It seems simple conceptually and easy to implement due to the fact that the nozzles are located together with burners and OFA nozzles on the same panels. In addition, such a syngas injection preserves the tangential motion of the gas and coal dust mixture. At the same time, the location of syngas nozzles allows providing gaseous co-fuel into the substoichiometric zone which translates into reducing the intensity of $\mathrm{NO}_{\mathrm{x}}$ formation. However, such a secondary fuel injection causes the maximum temperature zone moving up the combustion chamber takes place (Fig.5 and 6), which limits the further increase of percentage share of syngas in its co-firing with coal. As the syngas is moist and contains hydrogen, there is an increase in the moisture content in the exhaust gas (Fig.7).

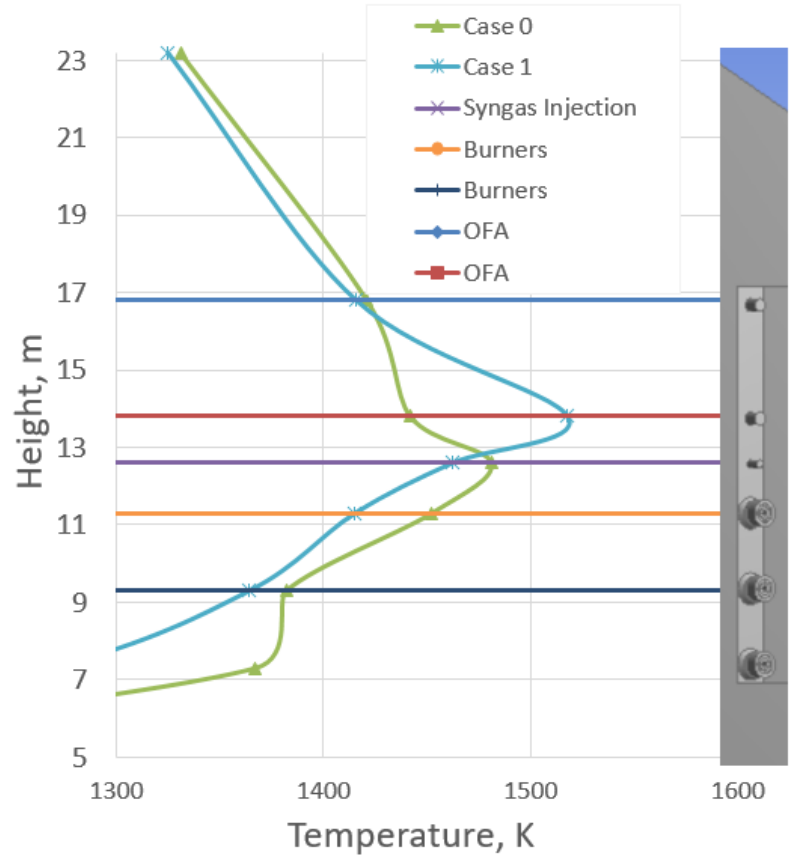

Fig. 5. Mean temperature along the furnace elevations.
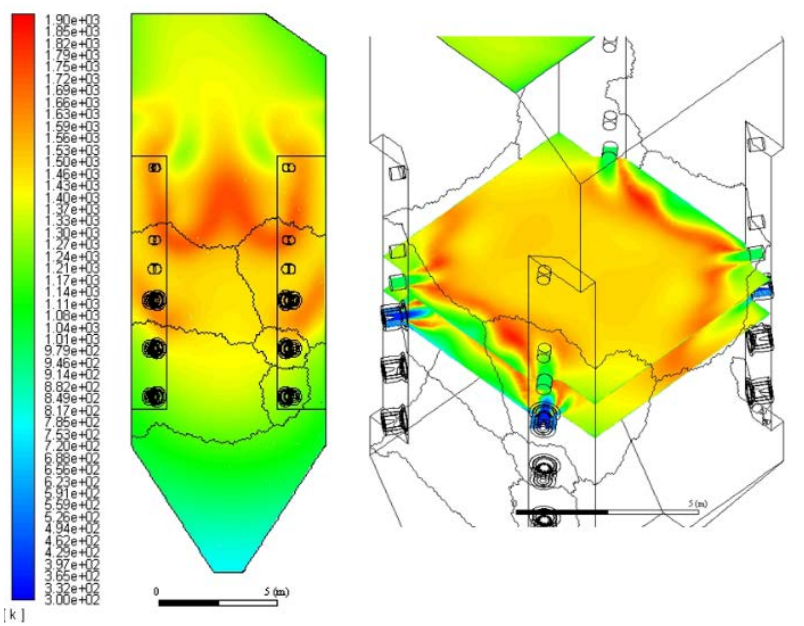

Fig. 6. Temperature $[\mathrm{K}]$ profiles in the furnace (Case 1).

The expected cooling effect caused also by the injected gas temperature is only slightly visible above the upper row of OFA nozzles (Fig.5). The distribution of oxygen in the furnace has a similar character as in the case of coal combustion. In the proposed case of co-firing, the protective nature of increased oxygen concentration near the walls of the combustion chamber is not disturbed (Fig.8). The tangential nature of the air, exhaust gas, syngas and coal dust mixture flow (Figs. 9 and 10), resulting from the location of burners, OFA and syngas nozzles, leads also to the lowering the maximum oxygen concentration above the OFA nozzles, which translates into $\mathrm{NO}_{\mathrm{x}}$ emission reduction. 


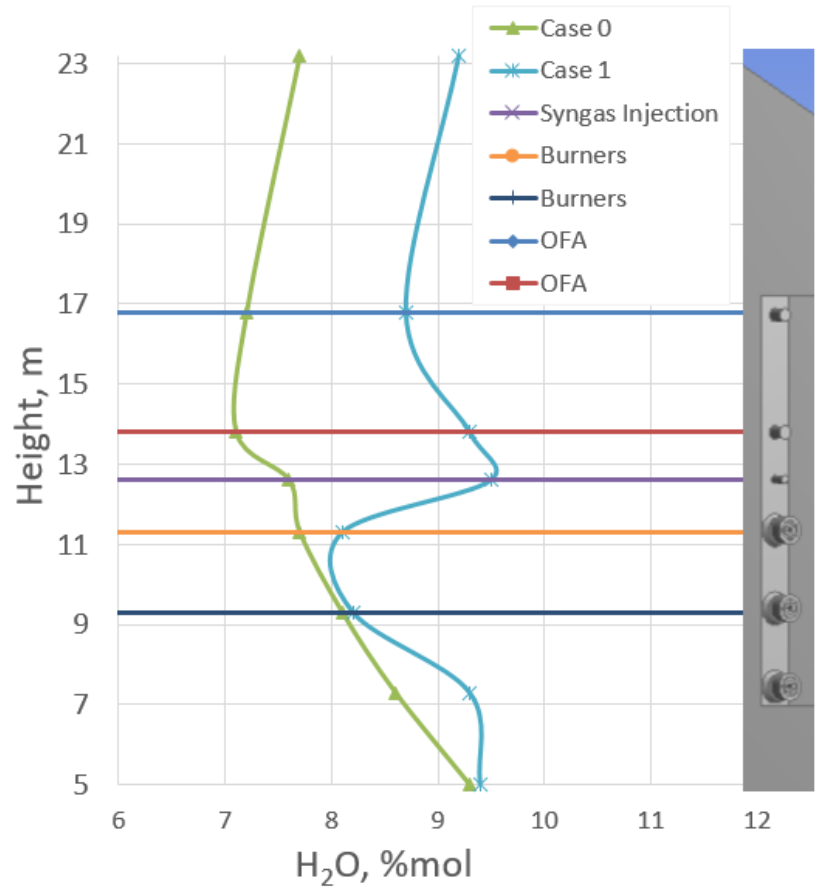

Fig. 7. Mean $\mathrm{H} 2 \mathrm{O}$ concentration along the furnace elevations.

Attention is drawn to the fact that Case 1 offers the residence time $(>2 s)$ of syngas particles in a zone, in which the temperature is higher than 1123K (Fig.11). Such a time is required by environmental protection regulations to safely co-fire coal with waste derived syngas. The results of numerical simulations of the woody biomass-derived syngas co-firing with coal prove that the reduction in $\mathrm{NO}_{\mathrm{x}}$ emission in the furnace exit (Fig. 12) relative to the baseline (no syngas) achieved with $15 \%$ heat input is equal to about $26 \%$ (310 vs. 397 $\mathrm{mg} / \mathrm{Nm}^{3}, 6 \% \mathrm{O}_{2}$ ).
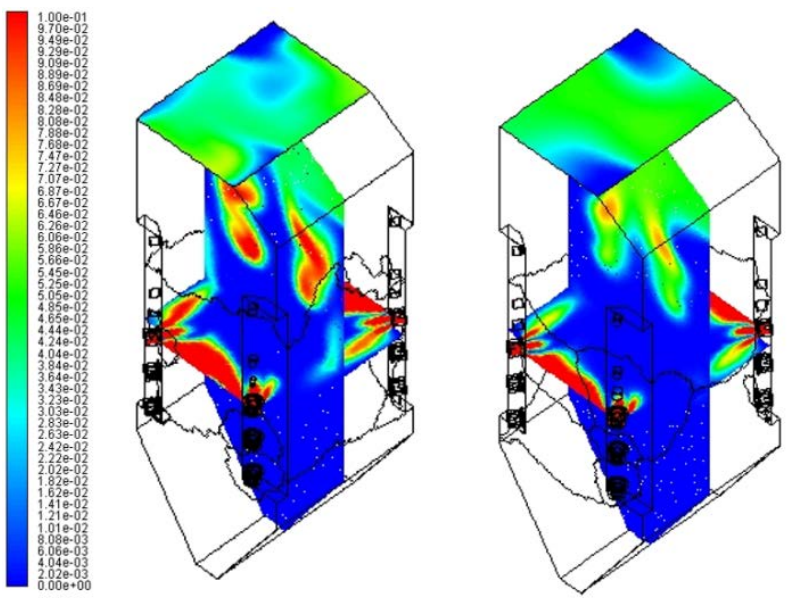

Fig. 8. $\mathrm{O}_{2}$ mole fraction profile in the furnace (Case 0 and Case 1).
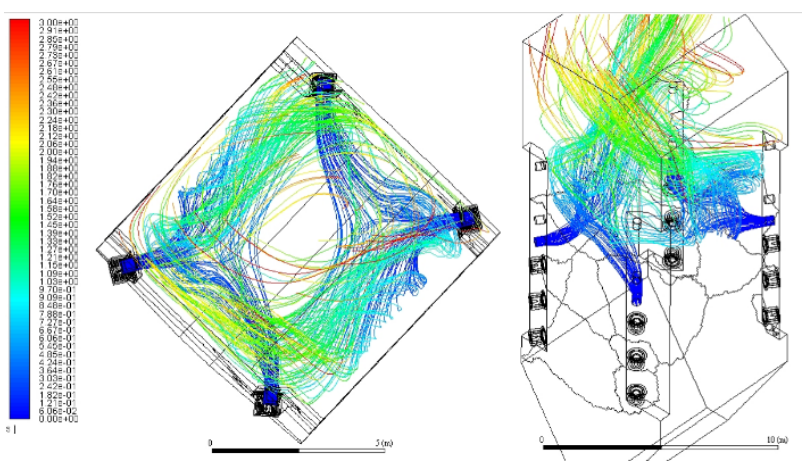

Fig. 9. Pathlines released from the dedicated syngas nozzles for Case 1.

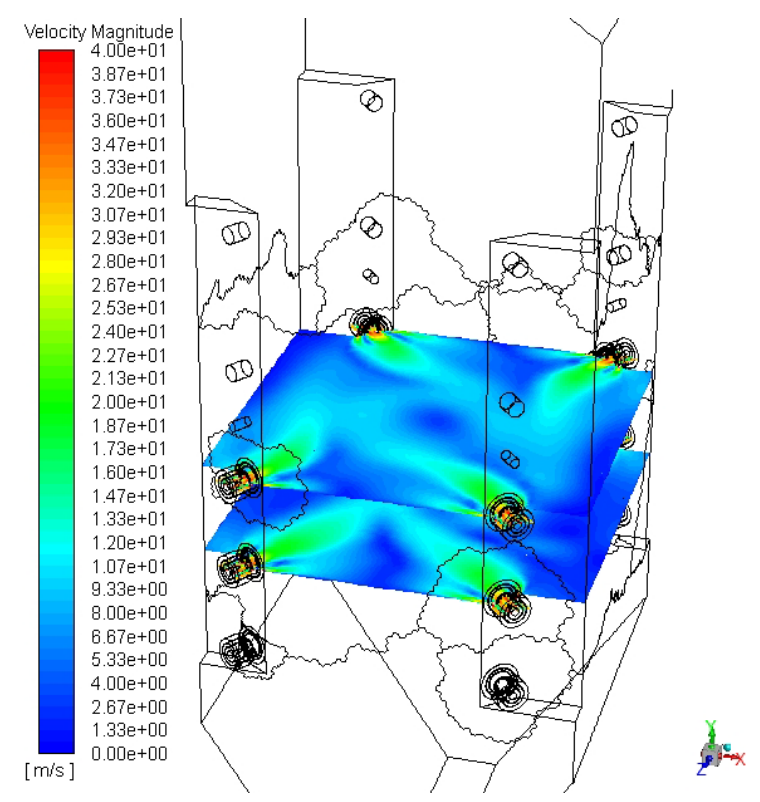

Fig. 10. Velocity magnitude in the furnace (Case 0 and Case 1).
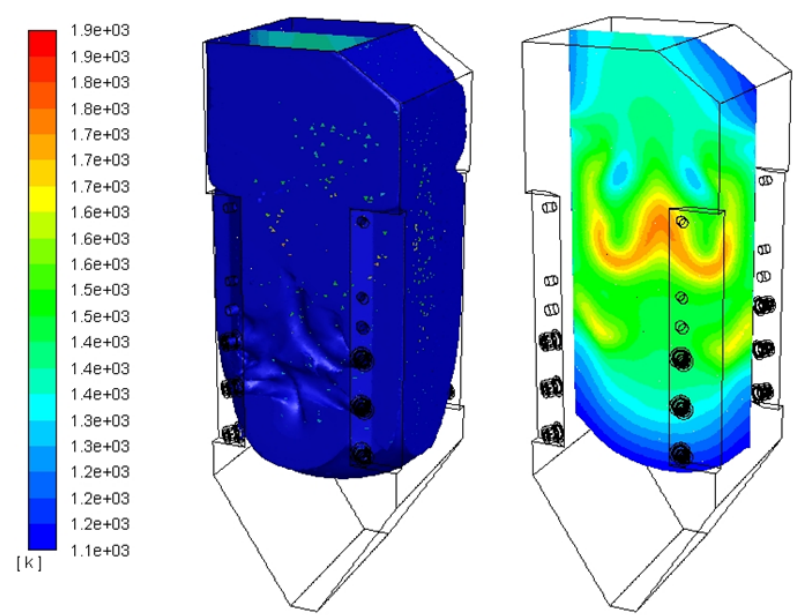

Fig. 11. Furnace zone at temperatures higher than $1123 \mathrm{~K}$ (Case 1). 
The syngas injection was accompanied by a change of air distribution in the combustion chamber. The reduced amount of combusted coal dust allowed to move the part of air from the burners to the OFA nozzles. This way, a constant fuel/air ratio in the burner zone and the total mass flow rate of air supplied to the combustion chamber remained unchanged.
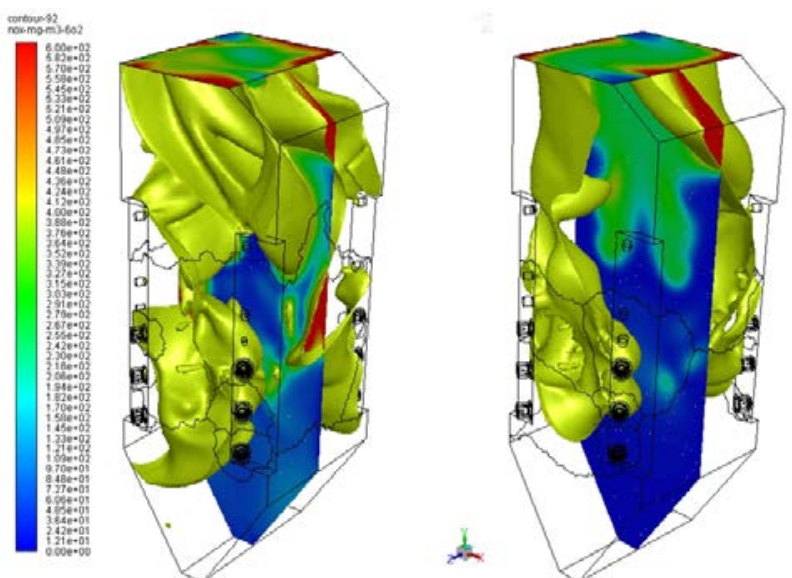

Fig. 12. Comparison of $\mathrm{NO}_{\mathrm{x}}$ values $\left[\mathrm{mg} / \mathrm{Nm}^{3}\right]$ (Case 0 and Case 1) and iso-surface of $\mathrm{NO}_{\mathrm{x}}=400 \mathrm{mg} / \mathrm{Nm}^{3}$.
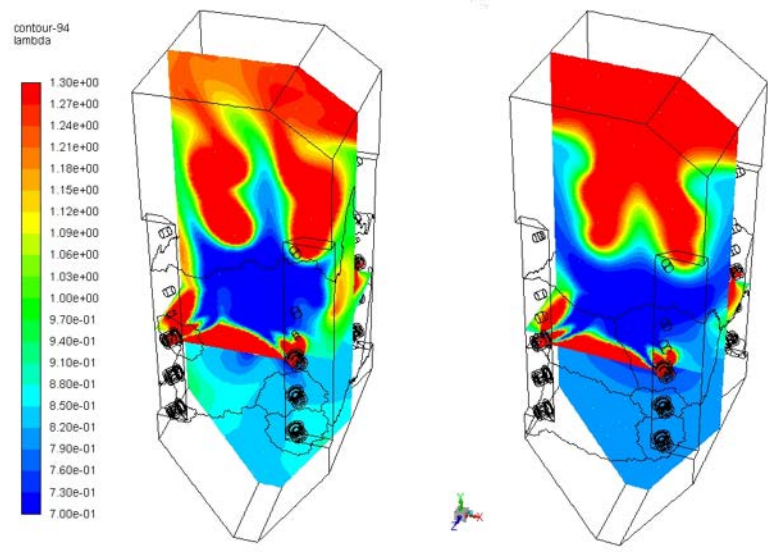

Fig. 13. Excess air ratio distribution in the furnace (Case 0 and Case 1).

The applied procedure allows the boiler operation without changes of excess air coefficient (Fig.13) corresponding to Case 0 in each characteristic zone of the furnace. It also ensures burnout of the char particles and comparable average CO concentration (Fig.14) in two simulated cases of syngas co-firing with coal. The excess air (i.e. stoichiometry) distribution along the furnace elevations proves that the proposed option of the in-direct biomass co-firing can be considered as the development of air staging technique based on the use of additional gaseous fuel. A relatively low height difference between the upper level of the burners and the OFA nozzles offers only a little space in which the efficient conventional syngas reburning cannot be developed. However, limiting the above considerations to the boiler operation at full load $(100 \%)$, it seems that one can create stoichiometry distribution favoring the conventional reburning by turning off the upper row of burners and turning on the lower row of burners inactive in our simulations. It is apparent that such a syngas reburning configuration requires modification of the amount of air supplied to the burners. This suggestion is just one of many reasons for further simulations of dualfuel combustion in a tangential PC-fired boiler of type OP-230.
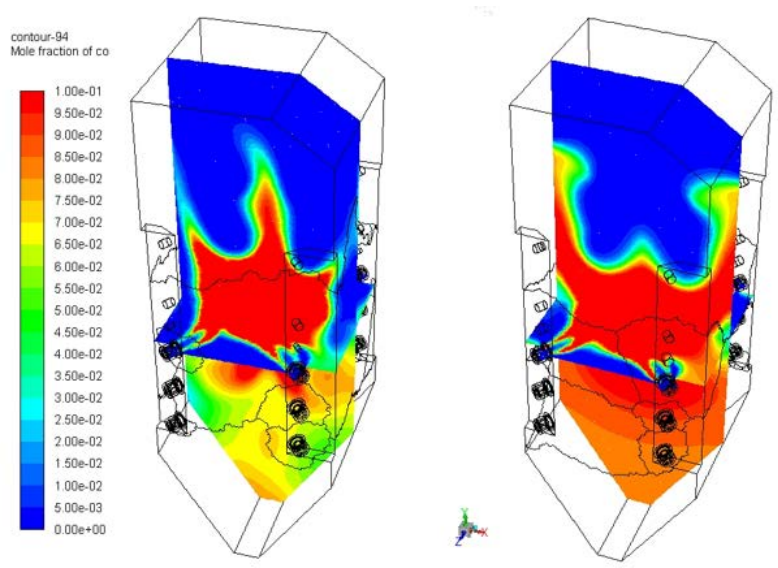

Fig. 14. CO mole fraction profile in the furnace (Case 0 and Case 1).

\section{Conclusions}

All the numerical tests were performed with injection of a supplemental fuel through dedicated nozzles as it is a solution offering great flexibility in the volumetric syngas flow rate. This facilitates the selection of syngas having the heating value suitable for ensuring the heat replacement postulated a priori. In addition, a set of available nozzles enables a freer choice of gas injection velocity for a given boiler load. The results obtained show that the proposed modifying of the inexpensive standard air staging technique in a tangential PC-fired boiler of type OP-230 cannot fully meet the prospective environmental protection regulations relating to levels of NOx emissions without combining with low-cost, selective non-catalytic reduction (SNCR) methods. Probably a similar situation will occur in the case of a boiler of the same type with low-emission burners on the front wall and syngas nozzles at the elevation of the bottom row of burners. Such a conclusion results from our own calculation results that have not been published yet. However, the adopted location of new nozzles dedicated to supplying syngas to the furnace is just one of many possible options that can be considered. Thus, our next approaches will be focused primarily on both the possible intensification of $\mathrm{NO}_{\mathrm{x}}$ reduction due to the location of syngas nozzles below the burners and the creation of conventional syngas reburning configuration. It is also advisable to show the sensitivity of a given dual fuel combustion on co-fuel composition and syngas heat input. Only then we will be able to say whether an older mid-sized tangential PC-fired boiler of type OP-230 can be effectively retrofitted by means of the improvement of the air staging via the dual-fuel technique based on the indirect co-firing technology. 


\section{References}

1. A.J. Minchener, Fuel 84 (17), 2222-2235 (2005)

2. R.W. Breault, Energies 3 (2), 216-240 (2010)

3. P. McKendry, Bioresource Technol 83 (1), 55-63 (2002)

4. R.P. Fernando, IEA Clean Coal Centre, London, UK, CCC/158 (2009)

5. D.L. Granatstein, IEA Bioenergy Agreement - Task 36, Natural Resources Canada/CANMET Energy Technology Centre (CETC) November (2002)

6. D.L. Granatstein, IEA Bioenergy Agreement - Task 36, Natural Resources Canada/CANMET Energy Technology Centre (CETC) September (2002)

7. Y. Ryckmans, F. Van den Spiegel, http://www.laborelec.com/docs/articles/lbe_art_CO MB006_uk.pdf.

8. R.P. Fernando, IEA Clean Coal Centre London, UK, CCC/194 (2012)
9. http://biofuelregion.se/wp-content/uploads/MauriBlomberg-Vaskilouden-Voima-Oy.pdf

10. K.T. Wu, H.T. Lee, C.I. Juch, H.P. Wan, H.S. Shim, B.R. Adams, S.L. Chen, Fuel 83, 1991-2000 (2004)

11. C. Dong, Y. Yang, R. Yang, J. Zhang, Applied Energy 87, 2834-2838 (2010)

12. W.P. Adamczyk, S. Werle, A. Ryfa, Applied Thermal Engineering 73(1), 343-350 (2014)

13. S. Kalisz, M. Pronobis, D. Baxter, Energy 33, 17701778 (2008)

14. K. Valler, A. Wopera, A.B. Palotas, K.J. Whitty, 4th European Combustion Meeting, ECM, Vienna, Austria 14-17 (2009)

15. ANSYS ${ }^{\circledR}$ Academic Research. Fluent Manual, Release 19.0

16. Technical documentation of the boiler OP-230, Siekierki CHP Plant, Warsaw

17. S. Poskrobko, The First Science \& Technology Conference „Modern technologies and power engineering equipment" Cracow 503-517 (2007) 